\title{
Simulating hydrological responses with a physically based model in a mountainous watershed
}

\author{
Q. Xu ${ }^{1,2,3}$, X. Chen ${ }^{1,4}$, J. Bi ${ }^{5}$, R. Ouyang ${ }^{6,7}$, and L. Ren ${ }^{1}$ \\ ${ }^{1}$ The State Key Laboratory of Hydrology-Water Resources and Hydraulic Engineering, \\ Nanjing, Jiangsu, P. R. China \\ ${ }^{2}$ Hydrology and Water Resources Department, NHRI, Nanjing Jiangsu, P. R. China \\ ${ }^{3}$ Research Centre of Climate Change, MWR, Nanjing Jiangsu, P. R. China \\ ${ }^{4}$ College of Hydrology and Water Resources, Hohai University, Nanjing, P. R. China \\ ${ }^{5}$ School of Computer Science and Technology, XiDian University, Xi' an, Shanxi, P. R. China \\ ${ }^{6}$ Bureau of Comprehensive Development Ministry of Water Resources, Beijing, P. R. China \\ ${ }^{7}$ Key Laboratory of Water Cycle \& Related Land Surface Processes, Institute of Geographic Sciences and \\ Natural Resources Research, Chinese Academy of Sciences, Beijing, P. R. China \\ Correspondence to: Q. Xu (royhsu1999@aliyun.com)
}

Received: 11 March 2015 - Accepted: 11 March 2015 - Published: 11 June 2015

\begin{abstract}
A physical and distributed approach was proposed by Reggiani et al. (1998) to describe the hydrological responses at the catchment scale. The rigorous balance equations for mass, momentum, energy and entropy are applied on the divided spatial domains which are called Representative Elementary Watershed (REW). Based on the 2nd law of thermodynamics, Reggiani (1999) put forward several constitutive relations of hydrological processes. Associated with the above equations, the framework of a physically based distributed hydrological model was established. The crucial step for successfully applying this approach is to develop physically based closure relations for these terms and simplify the set of equations. The paper showed how a theoretical hydrological model based on the REW method was applied to prosecute the hydrological response simulation for a humid watershed. The established model was used to carry on the long-term (daily runoff forecasting) and short-term (runoff simulation of storm event) hydrological simulation in the studied watershed and the simulated results were analysed. These results and analysis proved that this physically based distributed hydrological model can produce satisfied simulation results and describe the hydrological responses correctly. Finally, several aspects to improve the model demonstrated by the results and analysis were put forward which would be carried out in the future.
\end{abstract}

\section{Introduction}

Simulation and prediction of hydrological responses at the catchment scale is a grand challenge in the hydrological research. The current generation of physically based, distributed hydrological models for the upscaling of point-scale balance equations, as set out by Freeze and Harlan (1969), have the drawback that there is no a priori perception about how the micro-scale processes interact with each other and therefore cannot account for the self-organized features that emerge at the macro-scale, i.e. catchment scale, as a result of these interactions (McDonnell et al., 2007). Meanwhile, models such as SHE (Abbott et al., 1986), THIHMS-SW (Ni et al., 2008), among many others, are often criticized for their excessive complexity, parameter identifiability and thus uncertainty in comparison with limited data availability and excessive computational demands.

The REW approach first proposed by Reggiani et al. (1998) provides a general framework to incorporate all possible emergent behaviors of the hydrological system parameterized directly at the catchment scale. By coupling appropriate closure relationships to the balance equations to make the system of governing equations determinate (Reggiani, 1999), the REW approach has the potential to repre- 


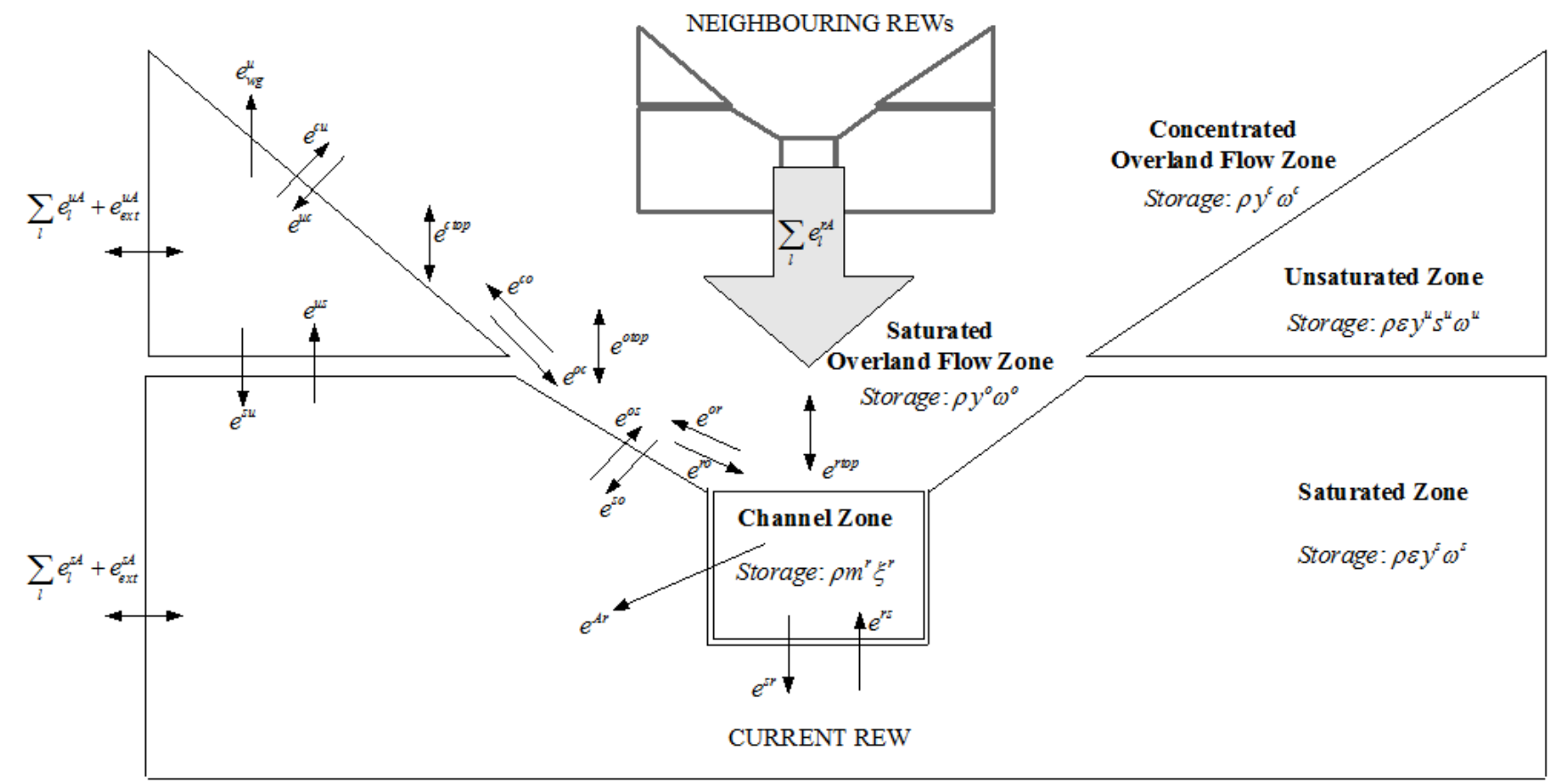

Figure 1. Schematized profile of a REW water balance and associated mass balance fluxes.

sent the net effects of the spatial and temporal heterogeneity of micro-scale processes (Lee et al., 2007). Several hydrological models based on REW approach were developed, such as CREW (Lee et al., 2005a), REWASH model (Zhang and Sevenije, 2005), TH model (Tian, 2006), and applied to simulated hydrological responses to real catchments (Reggiani and Rientjes, 2005; Lee et al., 2005b; Zhang and Savenije, 2005; Tian, 2006; Mou et al., 2008). Despite all this progress, these models are performed almost in arid or semi-arid area, and the performance of REW approach at humid catchment has not been reported. However, simulation and prediction of hydrological responses in humid area are crucial important for sustainable water management and hazard mitigation. This paper will serve as an extension to application of REW approach, and aims to demonstrate the capability of a generalized REW-based model for long-term streamflow modelling and for short-term flood predicting in humid regions.

This paper is organized as follows. In Sect. 2 we start with a brief review of REW approach, including theory and balance equations based on the previous studies. In Sect. 3, we will introduce the humid study area, including precipitation, evapotranspiration, vegetation, land use etc. Following this, in Sect. 4, after describing the data in this research, the REW approach will be applied in the humid study area and the results of simulation will be analysed. This will be followed, in Sect. 5 , by a summary of the main results and conclusions.

\section{Overview of the representative elementary watershed approach}

The REW is defined as the smallest and most elementary unit into which the watershed can be discretized for a given time scale of interest, and as the functional unit representative of other sub-entities of the entire watershed. Each REW consists of five model zones, i.e. sub-regions, in which water fluxes are simulated based on a coupling procedure of mass, momentum, energy and entropy balance equations. Simulated flows are (1) unsaturated zone flow (uzone), (2) saturated zone flow (s-zone), (3) saturation overland flow (o-zone), (4) concentrated overland flow (c-zone), which is commonly known as Hortonian overland flow, and (5) channel flow (r-zone). The ensemble of REWs constituting the catchment communicate with each other by exchanging mass, momentum and energy through the inlet and outlet sections of the associated channel reaches, and laterally through the exchange of groundwater and soil moisture across the soil mantle separating REWs. In addition, the subregions within each REW also exchange fluxes of mass, momentum and energy internally within the REW across the interfaces separating these sub-regions. Figure 1 presents in more detail the assumed sub-regions making up the spatial domain of a typical REW, and the various mass exchange fluxes across sub-region and REW boundaries.

The REW scale balance equations for mass, momentum, energy and entropy are established. With the aid of the 2nd law of thermodynamics, constitutive relationships are derived for the exchanges of mass and momentum fluxes 
across these boundaries. Following this, the closure relations governing the mass and momentum exchange are investigated. By substituting the parameterized mass and momentum exchange terms into the respective conservation equations, and by projecting the momentum balance equations along the global reference system, the set of parameterized balance equations for mass and momentum are obtained. Following simplifying the set of balance equations, the hydrological model based on REW approach is constructed with 9 balance equations for mass and momentum exchange, and 9 independent unknowns. Finally, hydrological responses will be simulated by solving the set and getting the numerical solutions.

\section{Study area and data collection}

\subsection{Study area}

The Huangnizhuang catchment $\left(31^{\circ} 06^{\prime}-31^{\circ} 42^{\prime} \mathrm{N}\right.$ and $115^{\circ} 21^{\prime}-115^{\circ} 43^{\prime} \mathrm{E}$ ) has a drainage area of $805 \mathrm{~km}^{2}$ and lies within the Shiguan River basin, a first-order southern tributary of the Huaihe River, Anhui Province, China. There are four rainfall stations and one discharge station in the catchment. The mean annual temperature of this catchment is $11-16^{\circ}$ and mean annual precipitation is $1077 \mathrm{~mm}$. However, the precipitation in the rainy season accounts for almost $50-80 \%$ of annual total.

The Huangnizhuang catchment contains a range of topographical settings, including highly mountainous and hilly areas (with a maximum elevation of $1495 \mathrm{~m}$ ) where stream flow velocities are high, as well as low alluvial plains where the drainage network is well developed. As such the Shiguan River Basin was selected as the intensified observation field site for the HUBEX (Huaihe River Basin Experiment) project as a component of GAME (the GEWEX Asian Monsoon Experiment), a part of the Global Energy and Water Cycle Experiment (GEWEX), supported financially by National Natural Science Foundation of China.

According to the topographic data and the area of Huangnizhuang watershed, the case watershed was divided into 9 REWs in this study. Figure 2 presents the study watershed, the rainfall/ discharge station in this watershed, and the REWs.

\subsection{Data collection}

\subsubsection{Topographic data}

The digital elevation model (DEM) is one of the most important data sets required for the REW models. In this study, the DEM was derived from the GLOBE (Global Land One-kilometre Base Elevation) data set with a horizontal resolution of 30 arcsec (approximately $1 \mathrm{~km}$ ). Using Arcgis/Arcview pre-process to remove pits, the flow direction of every grid was identified and the basin was delineated.
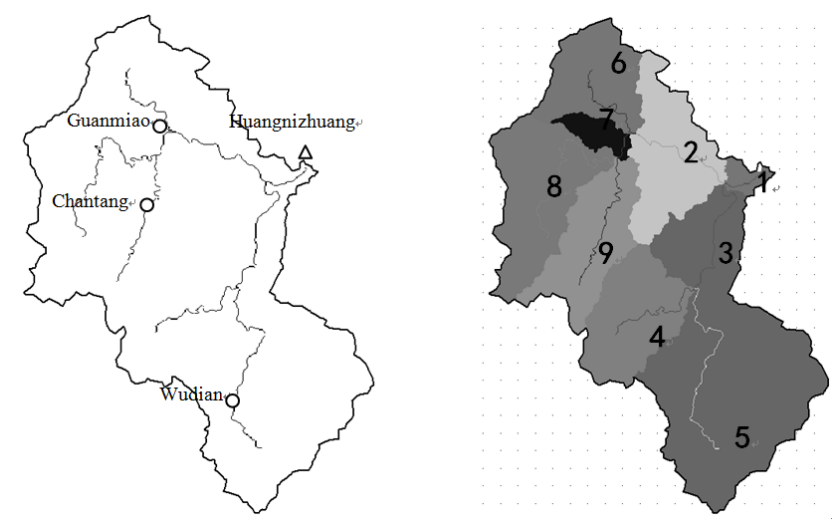

Figure 2. The location of the study area and the rainfall/discharge station.

\subsubsection{Land cover data}

The land cover, another important input data category, was downloaded from United States Geological Survey (USGS), using the IGBP (International Geosphere Biosphere Programme) classification scheme which classifies the global land cover into 17 types with $1 \mathrm{~km}$ spatial resolution. In the Huangnizhuang catchment, there are only six categories. The land cover with the largest area is woodland, which accounts for $81.038 \%$, followed by wooded grassland, accounting for $9.207 \%$. The deciduous broadleaf forest and mixed forest account for 3.920 and $2.826 \%$, respectively, with crop land and Evergreen needleleaf forest comprising $3.009 \%$.

\subsubsection{Soil type data}

The Food and Agriculture Organization (FAO) soil map was also used in this study. The Huangnizhuang catchment is composed of two categories of soil, which are represented as the content percentage of sand, silt and clay. Using the USDA (United States Department of Agriculture) soil triangle, the categories were transferred into USDA soil classifications which can assess field capacity and moisture content at wilting point for each soil type.

\subsubsection{NDVI data}

The NOAA/AVHRR (National Oceanic and Atmospheric Administration/Advanced Very High Resolution Radiometer) NDVI data set for monthly temporal resolutions with $8 \mathrm{~km}$ spatial resolution were publicly available from Pathfinder AVHRR Land Data. The subsets were then transferred into Lat/Lon projection and subdivided into $30 \mathrm{arcsec}$ grid spacing without interpolation to match the spatial resolution of DEM. 
Table 1. Results of daily runoff simulation using the REW approach.

\begin{tabular}{lccccccccc}
\hline Parameters & \multicolumn{10}{c}{ Number of REW } \\
\cline { 2 - 10 } & 1 & 2 & 3 & 4 & 5 & 6 & 7 & 8 & 9 \\
\hline$\alpha^{u s}$ & 6.54 & 6.54 & 6.54 & 6.54 & 6.38 & 5.77 & 6.54 & 6.02 & 6.54 \\
$\alpha^{c u}$ & 1.00 & 1.00 & 1.00 & 1.00 & 0.96 & 0.82 & 1.00 & 0.94 & 1.00 \\
$\alpha_{w g}^{u}$ & 152 & 152 & 152 & 152 & 138 & 121 & 144 & 129 & 152 \\
$\alpha^{o r}$ & 1.55 & 1.46 & 1.38 & 1.31 & 1.28 & 1.26 & 1.33 & 1.26 & 1.31 \\
$\alpha^{c o}$ & 1.30 & 1.31 & 1.32 & 1.35 & 1.42 & 1.45 & 1.37 & 1.45 & 1.35 \\
$\alpha_{1}^{s o}$ & 0.03 & 0.4 & 0.04 & 0.08 & 0.12 & 0.14 & 0.09 & 0.12 & 0.08 \\
$\alpha_{2}^{s o}$ & 0.83 & 0.87 & 0.88 & 1.00 & 1.33 & 1.52 & 0.96 & 1.33 & 1.00 \\
$\alpha_{3}^{s o}$ & 0.08 & 0.12 & 0.10 & 0.13 & 0.56 & 0.66 & 0.13 & 0.56 & 0.13 \\
$\beta_{1}^{\omega^{o}}$ & 8.20 & 8.80 & 8.95 & 10.5 & 10.5 & 10.5 & 9.32 & 10.5 & 10.5 \\
$\beta_{2}^{\omega^{o}}$ & 1.80 & 1.96 & 2.12 & 2.34 & 2.34 & 2.34 & 2.27 & 2.34 & 2.34 \\
$\beta_{3}^{\omega^{o}}$ & 15.8 & 15.9 & 15.9 & 16.0 & 16.0 & 16.0 & 16.0 & 16.0 & 16.0 \\
$\beta^{K^{u}}$ & 0.33 & 0.33 & 0.33 & 0.33 & 0.53 & 0.62 & 0.33 & 0.46 & 0.33 \\
\hline
\end{tabular}

\subsubsection{Meteorological data}

In the REW model, meteorological data such as mean daily temperature, mean diurnal temperature range, cloud cover, vapour pressure and wind speed were required. The IPCC (Intergovernmental Panel on Climate Change) Data Distribution Centre provides the monthly time series data of mean daily temperature, mean diurnal temperature range, cloud cover and vapor pressure at $0.5^{\circ} \times 0.5^{\circ}$ grids, and the CRU CL (Climate Research Unit/Climatology) 2.0 dataset provides the wind speed at 10 min grids, which was measured at majority of $10 \mathrm{~m}$ height.

\section{Results and analysis}

\subsection{Model establishment at the case watershed}

The case watershed was divided into 9 REWs, and the data for model running, including precepitation, initial state of watershed, model prameters etc. were discreted into 9 REWs. There are 12 pameters for each REW in this model, which can be analyzed and calculated theoretically from the content and velocity of gravity water and capillary water, hydraulic conductivity in unsaturated zone, etc. However, some of the data can not be observed in fact. In this paper, these 12 parameters were determined by calibration using a part of data series. The meaning and value of the parameters are presented in Table 1.

\subsection{Calculation of the potential evapotranspiration}

The actual evapotranspiration, i.e. $e_{w g}^{u}$ in Fig. 1, an important role in hydrological simulation, is defined as the less value of the potential evapotranspiration and transpiration by root uptake in the REW approach. Therefore, the potential evapotranspiration is calculated as an intermediate variable in the REW approach. So, the module of potential evapotranspi-

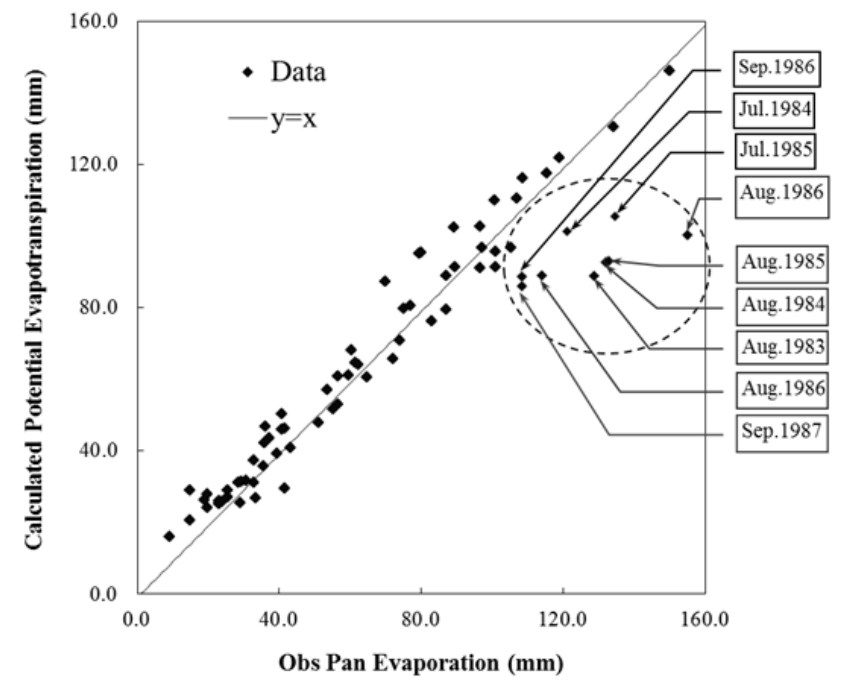

Figure 3. Comparison of the calculated results and observed evaporation.

ration in REW approach can be validated by compared the calculated results of the potential evapotranspiration in study catchment with the observed evaporation from water surface in the evaporation station.

In this paper, the average monthly leaf area index (LAI) is retrieved from NDVI data and the average potential evapotranspiration in study catchment from January 1982 to December 1987 are calculated. Figure 3 shows the comparison. There are 9 points deviate to the line $y=x$ obviously. The deviation of points all happened in July, August and September and the calculated results are all less than observed data. The average elevation of Huangnizhuang watershed is $479 \mathrm{~m}$ and the elevation of evaporation station, $35 \mathrm{~km}$ downstream of Huangnizhuang station, is $93 \mathrm{~m}$. The average temperature of the catchment is lower than the evaporation station, espe- 

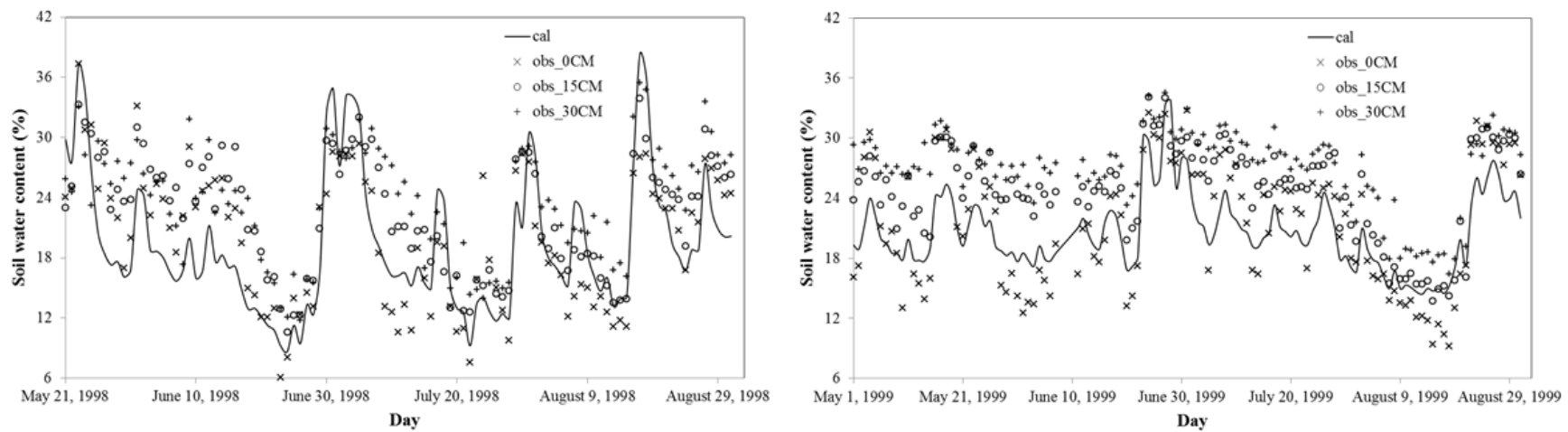

Figure 4. Comparison of the calculated results and observed soil water content.
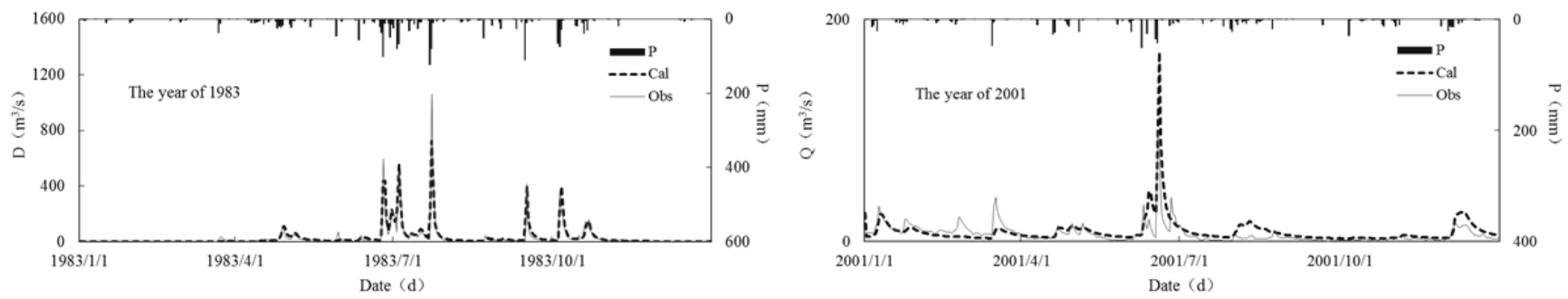

Figure 5. Comparison of the calculated results and observed daily hydrological processes.

cially in July, August and September. However the temperature is one of the most important factors to the evaporation. Meanwhile, the evaporation station is built in Jinzhai county town and the evaporation in city is impacted by human activity intensively. These two reasons mainly cause the deviation of these 9 points. The other 63 points lies two sides of the line $y=x$ uniformly. It illustrates that simulation based on REW approach performs well to calculate potential evapotranspiration in the humid watershed and the potential evapotranspiration module can provide precise input for the whole hydrological model.

\subsection{Calculation of the soil water content}

Soil water content, is another important role in hydrological simulation. Soil water saturation, $s^{u}$, is also calculated as an intermediate variable in the REW approach and soil porosity at Huangnizhuang station is 0.46 . So, soil water content, as another index, can be validated by compared the calculated results at Huangnizhuang station with the observed data.

Figure 4 presents the calculated results and observed soil water content at ground surface $(0 \mathrm{~cm}), 15 \mathrm{~cm}$ underground and $30 \mathrm{~cm}$ underground respectively. Calculated results of soil water content are more similar to the data observed form ground surface than others observed from $15 \mathrm{~cm}$ underground and $30 \mathrm{~cm}$ underground. Calculated results are almost less than observed data at $15 \mathrm{~cm}$ underground and $30 \mathrm{~cm}$ underground. The elevation of Huangnizhuang station is $170 \mathrm{~m}$ and the elevation of soil water content station, also in Jinzhai county town, is $93 \mathrm{~m}$. Soil water content station lies on the outlet of the whole basin, as the nearest evaporation and soil water content station to the study catchment, and the soil water content at this location is one of the maximum values in the whole basin theoretically in non-rainfall period. From 21 May 1998 to 23 May 1998, 28 June 1998 to 4 July 1998, 15 August 1998 to 18 August 1998, and 27 June 1999 to 30 June 1999, there are four rainfall events happened and the calculated results are more similar to observed data than it in other periods. With the whole trend calculated by the model illustrated in Fig. 4, it is indicated that hydrological model based on REW approach performs well in simulating soil water content in the humid area.

\subsection{Simulation of daily hydrological processes}

Data from 1980 to 1990, which includes precipitation, discharge, etc. are employed to calibrate the model, and data from 2001 to 2005 are employed to validate the model in simulating daily hydrological processes. Table 2 presents results of calibration and validation. Figure 5 shows the results of calibration and validation in the year 1983 and 2001. Nash, the Nash-Sutcliffe efficiency, reflects the accuracy of flood peak simulation, and $\mathrm{Re}$, the relative error of simulated value to observed runoff depth, reflects the simulation performance of water quantity.

In calibration, the average Nash of the model is 0.758 and all the $R e$ are in $\pm 20 \%$. In validation, these two indices are 0.751 and $\pm 20 \%$, respectivly. The average of Nash and Re 
Table 2. Results of daily runoff simulation using the REW approach.

\begin{tabular}{rrrrrrr}
\hline & Year & Nash & $\begin{array}{r}\text { Re of } \\
\text { Runoff } \\
(\%)\end{array}$ & Year & Nash & $\begin{array}{r}\text { Re of } \\
\text { Runoff } \\
(\%)\end{array}$ \\
\hline & & & & & -6.8 \\
& 1980 & 0.817 & -2.5 & 1986 & 0.795 & -6.1 \\
& 1981 & 0.629 & 19.6 & 1987 & 0.810 & -6.5 \\
Cal. & 1982 & 0.810 & -8.2 & 1988 & 0.718 & -6.2 \\
& 1983 & 0.879 & -7.9 & 1989 & 0.738 & 9.7 \\
& 1984 & 0.720 & 14.9 & 1990 & 0.724 & \\
& 1985 & 0.701 & -4.7 & & & \\
\hline \multirow{4}{*}{ Val. } & 2001 & 0.538 & 18.0 & 2004 & 0.853 & 8.5 \\
& 2003 & 0.829 & -6.4 & 2005 & 0.775 & -4.8 \\
\hline Avg & 0.762 & -10.0 & & & \\
\hline
\end{tabular}

are 0.756 and $0.9 \%$. In general, better model validation performance means that the corresponding parameter sets are well calibrated, and vice versa. Therefore, it indicates that not only a rigour structure is in REW model, but also hydrological model based on REW approach can be applied to simulate daily hydrologcial process in the humid or semihumid area. The model performed worse to the daily hydrological processes of year 2001 than it to the other years in validation. The calculated result is larger than observed data $18 \%$, and it is analysed as folloings. One hand, in calibration period (the year 1980 to 1990,11 years totally), the rainfall value are more than $1400 \mathrm{~mm}$ in 8 years, especially $2136 \mathrm{~mm}$ in 1987. The parameters of the model, calibrated from these data, reflect the situation of hydrologcial process in the wet years. However, the rainfall value in the year 2001 is only $907.0 \mathrm{~mm}$, that is to say a dry year. The same situation happens to the calculation of the year 1981. On the other hand, in a dry year, the natural runoff process are interfered by human activity intensively for taking water from the river. These two reasons mainly cause the significant relative error of runoff value in year 2001 and 1981.

\subsection{Simulation of flood events}

As the simulation of daily hydrological processes, data of 12 flood events are employed to validate the model. Besides the Nash and Re indices, the Td index, time difference of peak, is employed to assess the performance of REW model. Negative Td means happen time of simulated peak is ahead of observed data and positive Td means happen time of simulated peak is lagged to observed data. Table 3 presents these evaluating indicators and Fig. 6 shows the observed and simulated graphs of the No. 860715 flood.

The Nash of simulations of the 12 flood events are all beyond $0.70,8$ values among them are beyond 0.80 and 1 of them is beyond 0.90 . The Re of flood peak discharge simula-
Table 3. Results of hourly flood simulation at the Huangnizhuang station by REW approach.

\begin{tabular}{|c|c|c|c|c|}
\hline Flood no. & $\begin{array}{r}\text { Re } \% \text { of } \\
\text { flood } \\
\text { peak }\end{array}$ & $\begin{array}{l}\mathrm{Td} \\
\text { (h) }\end{array}$ & $\begin{array}{r}\text { Re } \% \text { of } \\
\text { runoff } \\
\text { depth }\end{array}$ & Nash \\
\hline 800716 & $\begin{array}{r}-3.7 \\
1.2\end{array}$ & $\begin{array}{r}4 \\
-1\end{array}$ & 9.7 & 0.857 \\
\hline 800719 & $\begin{array}{r}-1.2 \\
2.2\end{array}$ & $\begin{array}{l}1 \\
0\end{array}$ & -0.6 & 0.804 \\
\hline 800824 & 5.4 & 3 & -13.4 & 0.707 \\
\hline 820717 & -5.3 & -2 & 3.5 & 0.864 \\
\hline 820819 & $\begin{array}{r}-4.3 \\
3.5\end{array}$ & $\begin{array}{l}5 \\
0\end{array}$ & 4.6 & 0.761 \\
\hline 830624 & $\begin{array}{r}5.9 \\
-0.2\end{array}$ & $\begin{array}{l}0 \\
0\end{array}$ & 2.4 & 0.814 \\
\hline 830703 & $\begin{array}{r}1.8 \\
12.6\end{array}$ & $\begin{array}{l}3 \\
0\end{array}$ & -2.2 & 0.814 \\
\hline 830722 & $\begin{array}{r}4.6 \\
12.5\end{array}$ & $\begin{array}{l}0 \\
5\end{array}$ & 7.6 & 0.879 \\
\hline 850705 & -14.2 & 1 & -6.9 & 0.749 \\
\hline 860715 & $\begin{array}{r}-4.9 \\
-2.3 \\
2.1 \\
-2.6\end{array}$ & $\begin{array}{l}2 \\
0 \\
0 \\
0\end{array}$ & 4.7 & 0.901 \\
\hline 870820 & $\begin{array}{l}-4.4 \\
-2.2 \\
-0.6\end{array}$ & $\begin{array}{r}2 \\
-1 \\
1\end{array}$ & -0.9 & 0.810 \\
\hline 870828 & -5.8 & 2 & -10.6 & 0.730 \\
\hline
\end{tabular}

Notes: No. $800824,820717,850705,870828$ floods are single peak flood, and the other floods are compound peak flood.

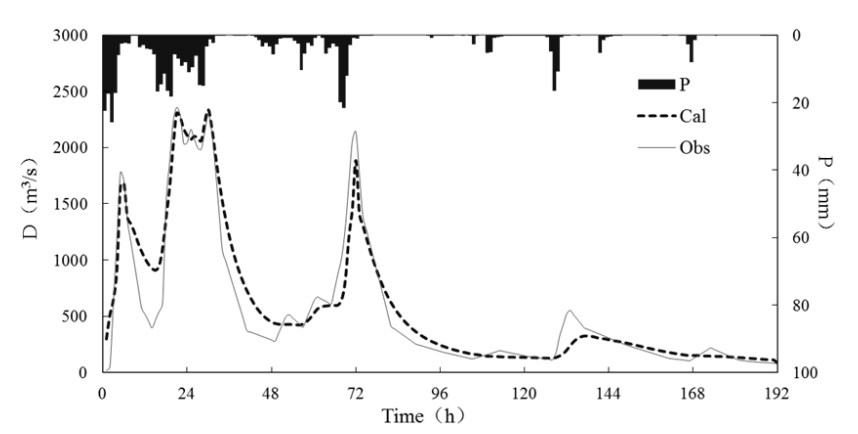

Figure 6. Comparison of the calculated results and observed flood No. 860715.

tion are all in $\pm 20 \%$, and 9 of them are in $\pm 10 \%$. The Re of runoff depth simulation are all in $\pm 20 \%$, and 10 of them are in $\pm 10 \%$. The Td of 9 flood events simulation are in $\pm 3 \mathrm{~h}$. The calculated results of 4 flood events, No. 800824, 820819, 850705 , and 870828 do not accord with the observed data well. No. 800824, 820819, and 870828 floods happened almost at the end of flood season in the year 1980, 1982 and 1987. In China, data of the cross section are updated before and after the flood season annually, and in the flood season, the cross section is changed intensively by the flood events. 
However, data of cross section, which are employed to calculate flood events happening at the end of the flood season, are measured before the flood season. This is the direct cause of error production. Through investigation, the cross section data are not updated before the flood season in the year 1985. So, the cross section data of the year 1984 are employed to simulate the No. 850705 flood events. Essentially, cause of error production of No. 850705 flood simulation is same to the other three flood events. Overall these results show the hydrological model based on REW approach performs well in simulation of flood events in a humid watershed.

\section{Conclusions}

Although great progress has been made in theoretical and applied aspects of the REW approach in recent years, application in humid or semi-humid area have been excluded in these applications. In this paper, the REW approach and REW-based model are overviewed. Subsequent model application to the Huangnizhuang watershed, a humid region in south-east China, showed very promising results, and demonstrated its utility for use in distributed hydrological modelling in humid or semi-humid area. In this paper, applied domain of REW approach is expanded significantly.

As stated by many researchers, the closure problem is one of the most crucial issues standing in the way of the REW approach becoming an alternative blueprint for distributed hydrological modelling. Consequently, future research in modelling can be better targeted towards both theoretical and experimental studies devoted to developing closure relations that parameterize the effects of sub-grid and sub-time variabilities. More and more parameters in REW approach will be determined by field experiments, not by calibrations. Since the links between landscape properties, process understanding, and model parameterizations are explicit in this framework, the REW approach is highly amenable to estimation of predictive uncertainty, and to efforts towards reduction of predictive uncertainty through targeted efforts to reduce model structure and parameter uncertainties. At the same time, the REW approach needs to apply in much more hydrological research domain, so that it can be validated and spread in the future.

Acknowledgements. This study has been supported in part by

1. National Natural Science Foundation of China (Grant No. 51109137),

2. National Natural Science Foundation of China (Grant No. 51209071),

3. National Natural Science Foundation of China (Grant No. 41101030),

4. Fundamental Research Funds for the Central Public Welfare Scientific Research Institutions (Grant No. Y513008),

5. Fundamental Research Funds for the Central Public Welfare Scientific Research Institutions (Grant No. Y510001).

\section{References}

Abbott, M. B., Bathurst, J. C., Cunge, J. A., O'Connell, P. E., and Rasmussen, J.: Introduction to the European hydrological system - Systeme Hydrologique Europeen, "SHE", 2: Structure of a physically-based, distributed modelling system, J. Hydrol., 87, 61-77, 1986.

Freeze, R. A. and Harlan, R. L.: Blueprint for a physically-based digitally-simulated hydrologic response model, J. Hydrol., 9, 237-258, 1969.

Lee, H., Sivapalan, M., and Zehe, E.: Representative Elementary Watershed (REW) approach, a new blueprint for distributed hydrologic modeling at the catchment scale - Numerical implementation, NATO Advanced Research Workshop, Moscow, 2005a.

Lee, H., Sivapalan, M., and Zehe, E.: Representative Elementary Watershed (REW) approach, a new blueprint for distributed hydrologic modeling at the catchment scale, The development of closure relations, in: Predicting Ungauged Streamflows in the Mackenzie River Basin, Today's Techniques and Tomorrow's Solutions, Canadian Water Resources Association (CWRA), Ottawa, Canada, 165-218, 2005b.

Lee, H., Zehe, E., and Sivapalan, M.: Predictions of rainfall-runoff response and soil moisture dynamics in a microscale catchment using the CREW model, Hydrol. Earth Syst. Sci., 11, 819-849, doi:10.5194/hess-11-819-2007, 2007.

McDonnell, J. J., Sivapalan, M., Vaché, K., Dunn, S., Grant, G., Haggerty, R., Hinz, C., Hooper, R., Kirchner, J., Roderick, M. L., Selker, J. and Weiler, M.: Moving beyond descriptions of watershed heterogeneity and process complexity - A new vision for watershed hydrology, Water Resour. Res., 43, W07301, doi:10.1029/2006WR005467, 2007.

Mou, L., Tian, F., Hu, H., and Sivapalan, M.: Extension of the Representative Elementary Watershed approach for cold regions: constitutive relationships and an application, Hydrol. Earth Syst. Sci., 12, 565-585, doi:10.5194/hess-12-565-2008, 2008.

Ni, G. H., Liu, Z. Y., Lei, Z. D., Yang, D. W., and Wang, L.: Continuous Simulation of Water and Soil Erosion in a Small Watershed of the Loess Plateau with a Distributed Model, J. Hydraul. Eng., 13, 392-399, 2008.

Reggiani, P.: Unifying framework for watershed thermodynamics: constitutive relationships, Adv. Water Resour., 23, 15-39, 1999.

Reggiani, P. and Rientjes, T.: Flux parameterization in the representative elementary watershed approach: Application to a natural basin, Water Resour. Res., 41, 1-18, 2005.

Reggiani, P., Sivapalan, M., and Hassanizadeh, S. M.: Unifying framework for watershed thermodynamics: balance equations for mass, momentum, energy and entropy, nd the second law of thermodynamics, Adv. Water Resour., 22, 367-398, 1998.

Tian, F., Hu, H., Lei, Z., and Sivapalan, M.: Extension of the Representative Elementary Watershed approach for cold regions via explicit treatment of energy related processes, Hydrol. Earth Syst. Sci., 10, 619-644, doi:10.5194/hess-10-619-2006, 2006.

Zhang, G. P. and Savenije, H. H. G.: Rainfall-runoff modelling in a catchment with a complex groundwater flow system: application of the Representative Elementary Watershed (REW) approach, Hydrol. Earth Syst. Sci., 9, 243-261, doi:10.5194/hess-9-243$2005,2005$. 